\title{
Metagenome reveals potential microbial degradation of hydrocarbon coupled with sulfate reduction in an oil-immersed chimney from Guaymas Basin
}

\author{
Ying $\mathrm{He}^{1,2}$, Xiang Xiao ${ }^{1,2}$ and Fengping Wang ${ }^{1,2 *}$ \\ ${ }^{1}$ State Key Laboratory of Microbial Metabolism, School of Life Sciences and Biotechnology, Shanghai, China \\ 2 State Key Laboratory of Ocean Engineering, Shanghai Jiao Tong University, Shanghai, China
}

Edited by:

Andreas Teske, University of North Carolina at Chapel Hill, USA

\section{Reviewed by:}

Melanie R. Mormile, Missouri

University of Science and

Technology, USA

Jinjun Kan, Stroud Water Research Center, USA

\section{*Correspondence:}

Fengping Wang, Laboratory of Microbial Oceanography, School of Life Sciences and Biotechnology, Shanghai Jiao Tong University, 800 Dongchuan Road, Shanghai 200240, China

e-mail: fengpingw@sjtu.edu.cn
Deep-sea hydrothermal vent chimneys contain a high diversity of microorganisms, yet the metabolic activity and the ecological functions of the microbial communities remain largely unexplored. In this study, a metagenomic approach was applied to characterize the metabolic potential in a Guaymas hydrothermal vent chimney and to conduct comparative genomic analysis among a variety of environments with sequenced metagenomes. Complete clustering of functional gene categories with a comparative metagenomic approach showed that this Guaymas chimney metagenome was clustered most closely with a chimney metagenome from Juan de Fuca. All chimney samples were enriched with genes involved in recombination and repair, chemotaxis and flagellar assembly, highlighting their roles in coping with the fluctuating extreme deep-sea environments. A high proportion of transposases was observed in all the metagenomes from deep-sea chimneys, supporting the previous hypothesis that horizontal gene transfer may be common in the deep-sea vent chimney biosphere. In the Guaymas chimney metagenome, thermophilic sulfate reducing microorganisms including bacteria and archaea were found predominant, and genes coding for the degradation of refractory organic compounds such as cellulose, lipid, pullullan, as well as a few hydrocarbons including toluene, ethylbenzene and o-xylene were identified. Therefore, this oil-immersed chimney supported a thermophilic microbial community capable of oxidizing a range of hydrocarbons that served as electron donors for sulphate reduction under anaerobic conditions.

Keywords: metagenome, deep sea, hydrothermal vent, chimney, Guaymas, biodegradation, hydrocarbon, sulfate reduction

\section{INTRODUCTION}

Deep-sea hydrothermal vents characterized by steep physicochemical gradients harbor a wide range of microorganisms in different ecological niches, including the high-temperature chimney matrix (Reysenbach and Shock, 2002). Deep-sea hydrothermal vent chimneys are the product of hydrothermal circulation and alteration of seawater entrained through geothermally heated subseafloor basalt, and subsequent precipitation of mental sulfides when hot vent fluids emerge into cold sea water (Von Damm, 1990). The geochemical disequilibria within and surrounding chimneys provide rich energy sources for microorganisms, as various reduced chemicals (such as sulfur, methane, and $\mathrm{H}_{2}$ ) are utilized as potential electron donors (Jannasch and Mottl, 1985; Distel et al., 1988; Lam et al., 2004; Petersen et al., 2011). The structures of these microbial communities are shaped primarily by variation of hydrothermal fluid composition, in particular $\mathrm{H}_{2}$ concentrations (Flores et al., 2011). Thanks to advances in sequencing technologies, molecular microbial diversity studies of deep-sea hydrothermal environments have made significant progress in understanding the geographic distributions of these microbial communities (Teske et al., 2002; Huber et al., 2007,
2010; Brazelton et al., 2010; Dick and Tebo, 2010; Roussel et al., 2011).

Despite the increased knowledge of the microbial diversity of deep-sea hydrothermal vents, much less was known about the metabolic potential and ecological functions of these communities, especially when considering that less than $1 \%$ of environmental microorganisms could be cultured under laboratory conditions (Amann et al., 1995). Metagenomic-based methods have provided unique opportunities to explore the features of microbial communities from diverse deep-sea hydrothermal vent environments. So far, metagenomes from two deep-sea hydrothermal vent chimneys have been published, from a carbonate white chimney at Lost City with relatively low temperature and high $\mathrm{pH}\left(<90^{\circ} \mathrm{C}, \mathrm{pH} 9-11\right)$ (Brazelton and Baross, 2009), and from a chimney sample collected from Juan de Fuca (Xie et al., 2011) characterized by high temperature and low $\mathrm{pH}$ fluids $\left(>300^{\circ} \mathrm{C}, \mathrm{pH} 2-3\right)$. Both metagenomes were found enriched in transposases, implying that horizontal gene transfer may be a common feature of hydrothermal vent chimney biosphere. Comparative metagenomic studies with more chimney samples from different deep-sea hydrothermal vents should be performed 
to reveal common features of the chimney-originated microbial communities.

The Guaymas Basin (Gulf of California) is a unique hydrothermal vent site, where emitted high-temperature fluids are influenced by the presence of a thick layer $(100-500 \mathrm{~m})$ of sediments (with $2-4 \%$ organic matter, OM). These sediments were formed by precipitation from the highly productive surface waters and terrigenous input (Von Damm et al., 1985). The venting fluids are characterized by an increase of $\mathrm{pH}$ (around 6.0), and a decrease in the highest temperature of fluids emitted on the seafloor $\left(270-325^{\circ} \mathrm{C}\right)$ (Von Damm et al., 1985). Therefore, the chimney sample from the Guaymas site would be an ideal sample for comparative metagenomic analysis together with the two published ones. In addition, Guaymas Basin is unique due to the fact that under high-temperature conditions, the $\mathrm{OM}$ in its rapidly accumulating sediments is pyrolized to petroleum-like hydrocarbon products, such as aliphatic and aromatic hydrocarbons, short-chain fatty acids, ammonia, and methane (Bazylinski et al., 1988; Welhan, 1988; Martens, 1990; Kawka and Simoneit, 1994). The hydrothermally active sediments of the Guaymas Basin were reported with intensive methane oxidizing and sulfate reducing activities (Jørgensen et al., 1990, 1992; Elsgaard et al., 1994; Weber and Jørgensen, 2002; Kallmeyer and Boetius, 2004). Various hydrocarbon degrading microorganisms which are using sulfate as the electron acceptor have been isolated from Guaymas Basin sites and similar marine habitats (Rüter et al., 1994; Galushko et al., 1999; Musat and Widdel, 2008; Kleindienst et al., 2012). Nevertheless, the metabolic potential, in particular for hydrocarbon degradation, of the whole microbial community from Guaymas vent chimneys has never been investigated. Therefore, comprehensive studies on biodegradation, in particular under anaerobic conditions, still remain to be conducted to characterize the structure and metabolic potential of microbial ecosystems with capability for hydrocarbon biodegradation.

In this study, the metagenome of an oil-immersed chimney in Guaymas Basin was analyzed to demonstrate the metabolic potential and ecological functions of the inhabited microbial community. Additionally, questions related to anaerobic biodegradation of hydrocarbons are addressed: do the microorganisms from this chimney community have anaerobic hydrocarbon degradation activities? If so, what kinds of hydrocarbons could be potentially degraded? Which groups of microorganisms are responsible for carrying out the degradations? Which processes are coupled/closely related to the degradation for electron transfer? Are there any features shared among different chimney-originated samples?

\section{MATERIALS AND METHODS

DNA EXTRACTION AND SEOUENCING

The sample 4558-6 under investigation represented the outer layer of a black-smoker chimney with preliminary venting fluid temperature $190^{\circ} \mathrm{C}$ (measured above the chimney prior to sampling), and was collected in Guaymas Basin $\left(27^{\circ} 0.9^{\prime} \mathrm{N}\right.$, $111^{\circ} 24.6^{\prime} \mathrm{W}$, depth $=2013 \mathrm{~m}$ ) by the HUV Alvin (supported by the R/V Atlantis) in November, 2009. The chimney (Figure A1) was kept at $-20^{\circ} \mathrm{C}$ immediately after sample collection, and stored with dry ice during transportation and stored at $-80^{\circ} \mathrm{C}$ in laboratory until further analyses. The genomic DNA was extracted from outer sections of all collected samples where highest DNA quantity was found. Isolation of DNA was conducted as described in a previous study (Wang et al., 2009). Metagenome pyrosequencing was performed according to company protocol on the 454 Life Sciences GS FLX system with a practical limit of $400 \mathrm{bp}$. All the sequences were deposited in the MG-RAST server.

\section{METAGENOMIC ANALYSIS AND ASSEMBLY}

Low quality sequencing reads were trimmed in Geneious 6.04 (Biomatters Ltd.) with default parameters. Technical replicates (Gomez-Alvarez et al., 2009) were removed with cd-hit (at 96\% sequence identity) (Niu et al., 2010). Shorter reads (<100 bp) were then excluded, and the remaining reads were assembled with Velvet (Zerbino and Birney, 2008). This metagenome from Guaymas Basin chimney was uploaded (MG-RAST ID: 4510962.3) and analyzed using MG-RAST (Meyer et al., 2008).

\section{METAGENOMIC SEQUENCE ANALYSIS}

Coding regions within the metagenome were predicted using FragGeneScan (Rho et al., 2010), and the predicted sequence features were then annotated (e-value $<1$ e-5) against M5NR protein database. 16S rRNA genes were predicted with HMM and BLASTN (e-value <1e-5) in webMGA (Wu et al., 2011), respectively. To analyze the taxonomic contents, all predicted gene features were subject to blastx (Altschul et al., 1997) searches against NCBI non-redundant (NR) database (e-value $<1 \mathrm{e}-5$, word size $=3$, multi hit window size $=40$ and low complexity filter on) and visualized in MEGAN (Huson et al., 2007). Each predicted sequence feature in the metagenome was assigned to a certain taxon when at least $75 \%$ of the BLAST hits of this query were from that specific taxon. Sequences with matches to the eggNOG (Powell et al., 2012), COG (Tatusov et al., 2003) and KEGG (Ogata et al., 1999) database were retrieved to build functional categories and reconstruct metabolic pathways.

\section{ANNOTATION OF SEOUENCES WITH DEGRADATION/METABOLIC ACTIVITIES}

Sequences that were annotated as enzymes in the degradation of cellulose and fatty acids were extracted and subject to manual examination. Annotated KEGG pathways in this metagenome were visualized in MEGAN to demonstrate the metabolic potential in the microbial community. Enzymes involved in the degradation of a few organic chemicals (such as benzene, toluene, ethylbenzene, and xylenes) were collected from the Biocatalysis/Biodegradation Database (BBD) of the University of Minnesota (Gao et al., 2010), an online web service that listed known degradation pathways for hundreds of chemicals/contaminants. Within this chimney metagenome, a sequence-similarity based search against BBD was conducted to identify candidate genes that were involved in the biodegradation of certain hydrocarbons. Sequences of previously reported anaerobic alkane degradation genes (Callaghan et al., 2010), benzylsuccinate synthase (bss) and alkylsuccinate synthase (ass), were retrieved from GenBank (accession no.: DQ826035, DQ826036, AJ001848, AB066263, AY032676, and AF113168) and searched against our Guaymas metagenome. 


\section{CLUSTERING ANALYSIS OF FUNCTIONAL CATEGORIES}

Clustering of functional categories (with KEGG annotation, e-value $<1$ e- 5 , min. identity of $30 \%$ and min. align. length of 15 a.a.) was conducted in MG-RAST (using ward with canberra distance metric based on normalized values) among metagenomes as following: Guaymas Basin chimney 4558-6 (MG-RAST ID: 4510962.3), Juan de Fuca chimney (MG-RAST ID: 4510965.3) (Xie et al., 2011), Lost City hydrothermal vent field (MGRAST ID: 4461585.3) (Brazelton and Baross, 2009), two biofilm samples from acid mine drainage (UBA and 5way, with MGRAST ID 4441137.3 and 4441138.3, respectively) (Tyson et al., 2004), a gutless worm (MG-RAST ID: 4441115.3) (Woyke et al., 2006), the North Pacific Subtropical Gyre microbial communities (the HOT project with depth of 10, 70, 130, 200, 500, 770 and $4000 \mathrm{~m}$, and with MG-RAST ID: 4441051.3, 4441057.4, 4441055.3, 4441041.3, 4441057.3, 4441062.3, and 4441056.3, respectively) (Delong et al., 2006) and a deeply buried sediments from Peru Margin (for sample original, am1mbsf, am16mbsf, am32mbsf and am50mbsf, and with MG-RAST ID: 4440960.3, 4440961.3, 4440973.3, 4459940.3, and 4459941.3, respectively) (Biddle et al., 2008). All metagenomes were stored in MG-RAST database.

\section{RESULTS}

\section{SEQUENCING SUMMARY AND COVERAGE}

Initially, as shown in Table $\mathbf{1}$, a total amount of 512,830 reads and $196,377,880 \mathrm{bp}$ of sequence data were generated by 454 pyrosequencing. After removing low-quality reads and technical duplicates, the remaining 504,915 reads (with an average length $383 \mathrm{bp}$ ) were assembled into 49,055 contigs (totaling $26,241,624 \mathrm{bp}$, with an average length of $543 \mathrm{bp}$ ). 187,308 singletons with an average length of $367 \mathrm{bp}$ could not be assembled. From this assembly, 52,366 gene features were predicted, 37,372 of which $(71.4 \%)$ were with known annotations. A rarefaction analysis of the final assembly was conducted based on the taxonomic information retrieved from annotation results in MG-RAST (Figure 1), which indicated that a reasonable number of individual genomes were sampled and covered in the metagenome.

\section{TAXONOMIC DIVERSITY BASED ON 16S rRNA GENE PREDICTION}

70 and 90 16S rRNA sequences were predicted from webMGA (Wu et al., 2011), with the use of HMM and BLASTN, respectively (Table 2). In both of the results, around $3 / 4$ (72.9 and 76.7\%,

Table 1 | Summary of sequences from the chimney sample 4558-6.

\begin{tabular}{ll}
\hline Properties & Value \\
\hline Clean reads & 504,915 \\
Base pairs & $193,336,182$ \\
GC content & $42 \%$ \\
Average read length & 383 \\
Singletons & 187,308 \\
Contigs & 49,055 \\
Average contig length & 543 \\
Best hit gene features with NR database & 37372
\end{tabular}

respectively) of all identified $16 \mathrm{~S}$ rRNA sequences were from bacteria. Deltaproteobacteria and Euryarchaeota had dominated the bacteria and archaea, respectively.

\section{PHYLOGENY FROM 454 PYROSEQUENCING DATA}

A total number of 37,372 predicted gene features were utilized to extract taxonomic information by BLASTing against the NCBI NR database. In total, 21,792 (58.3\%) and 11,249 (30.1\%) hits were assigned to bacteria and archaea (rules for taxonomic assignment were stated in "Materials and Methods"), respectively (Table A1). At the phylum level, Proteobacteria (9558, 25.6\%), Euryarchaeota $(9078,24.3 \%)$, Crenarchaeota (1354, 3.6\%), Firmicutes (786, 2.1\%), Thermotogae (725, 1.9\%), and Bacteroidetes $(607,1.6 \%)$ had the top matches (Figure 2). Taxa with most hits assigned were listed in Table 3. Notably, the majority of sequences in this chimney metagenome originated from the families Archaeoglobaceae, Thermococcaceae, and Desulfobacteraceae, and a high proportion $(>21.2 \%)$ of sequences potentially originated from sulfate reducing prokaryotes (SRP). Moreover, thermophilic sulfate reducing microorganisms, including bacteria (Thermodesulfobacteriaceae) and archaea (Archaeoglobaceae) were found predominant, highlighting their roles in reducing sulfates and/or sulfites to sulfides during energy metabolism under anaerobic conditions.

\section{FUNCTIONAL CATEGORY HITS DISTRIBUTION}

Major KEGG function categories were listed (Table 4) and ordered by the number of unique hits assigned to each category. Similar to a previous study on the chimney from hydrothermal vents (Xie et al., 2011), genes involved in Recombination and Repair were among the abundant categories (Table 4). In addition, transposaes were found to be highly enriched in this sample (Table A3), and genes participated in Chemotaxis and Flagellar Assembly was all identified with high abundance in this metagenome.

\section{DEGRADATION OF REFRACTORY OM AND PETROLEUM HYDROCARBONS}

Sequences coding for the complete degradation pathway of cellulose and fatty acids, as well as key enzymes involved in breakdown of lipid and pullulan were all identified in this metagenome (Table A2). Many of these identified enzymes were with thermorphilic-origin best hits (as marked with asterisk in Table A2). Peptidases were found to be of low abundance in this metagenome (data not shown). For anaerobic hydrocarbon degradation, sequences coding for benzylsuccinate synthase (bss) and alkylsuccinate synthase (ass), key enzymes in the fumarate addition pathway for the anaerobic oxidation of hydrocarbons (Callaghan et al., 2010), were identified (Table 5). In particular, gene candidates involved in BTEX (benzene, toluene, ethylbenzene, and xylenes) degradation were identified by searching against the BBD of the University of Minnesota (Gao et al., 2010) (Table 5). Additionally, to show the metabolic potential of this Guaymas sample in the degradation and remediation of organic contaminants (He et al., 2010), genes involved in the degradation of aromatic carboxylic acid (benzoate, phenylpropionate and phthalate), chlorinated aromatics (2- and 4-chlorobenzoate, 


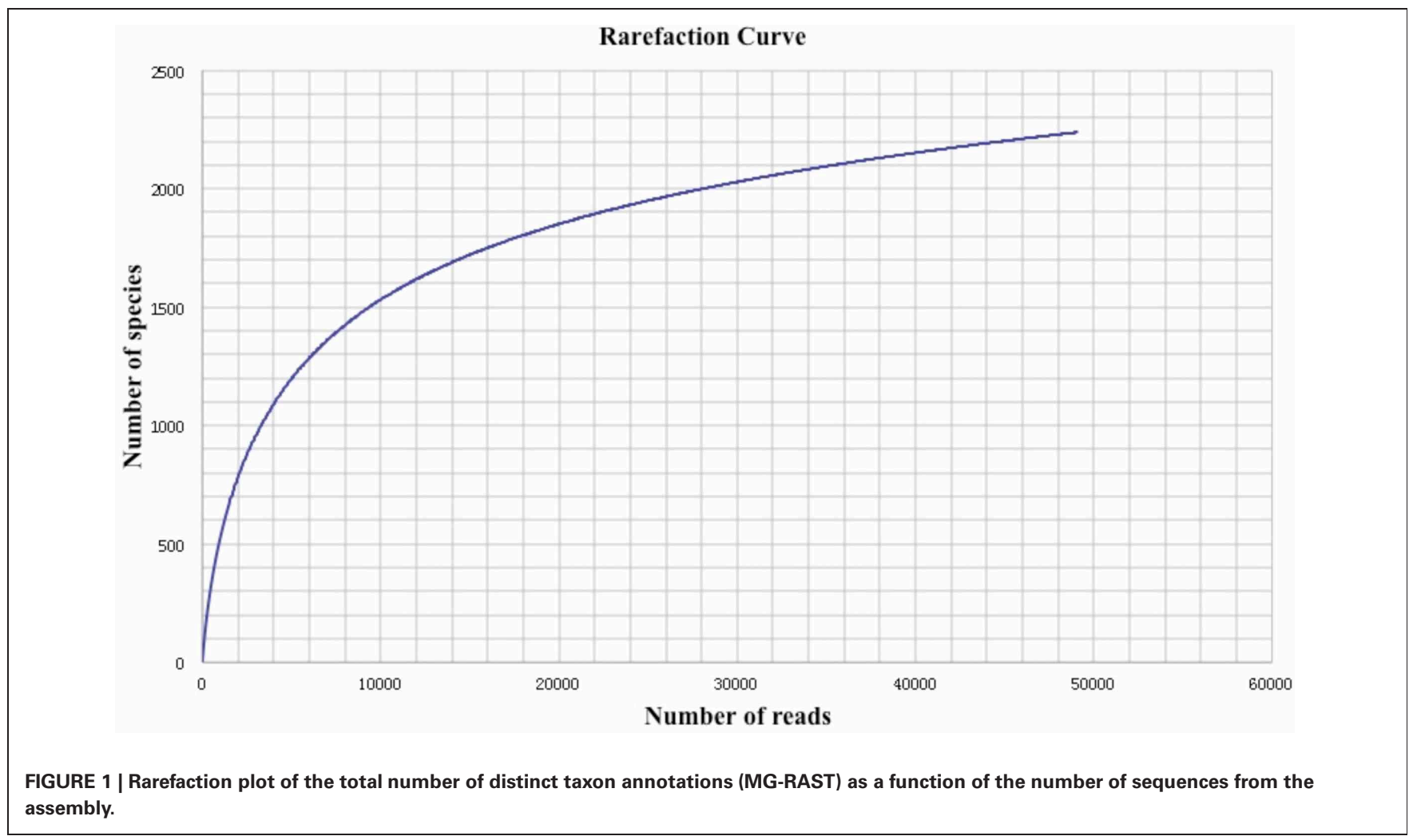

Table 2 | Taxonomic diversity based on 16S rRNA gene prediction from the metagenome.

\begin{tabular}{lll}
\hline Methods & $\begin{array}{l}\text { Domain [total no. } \\
\text { of sequences (\%)] }\end{array}$ & Diversity (\% in domain) \\
\hline HMM & Bacteria $(51,72.9)$ & $\begin{array}{l}\text { Deltaproteobacteria (25.4) } \\
\text { Gammaproteobacteria (21.6) } \\
\text { Epsilonproteobacteria (13.7) } \\
\text { Deferribacteres (7.8) }\end{array}$ \\
\cline { 2 - 3 } & Archaea $(19,27.1)$ & Euryarchaeota (63.2) \\
& Crenarchaeota/Thermoprotei (36.8) \\
\hline \multirow{2}{*}{ BLASTN } & Bacteria $(69,76.7)$ & Deltaproteobacteria (23.4) \\
& & Gammaproteobacteria (18.8) \\
& & Epsilonproteobacteria (12.5) \\
& & Acidobacteria (9.4) \\
& & Deferribacteres (7.8) \\
\cline { 2 - 3 } & & Euryarchaeota (52.4) \\
& & Crenarchaeota/Thermoprotei (47.6)
\end{tabular}

2,4,5-trichlorophenoxyacetic acid), heterocyclic aromatics (carbazole and dibenzothiophene), nitroaromatics (nitrobenzene and nitrophenol) as well as a few of other hydrocarbons (cyclohexane and tetrahydrofuran) were searched within the Guaymas metagenome. Notably, this chimney sample seemed to have the potential to degrade toluene, ethylbenzene and o-xylene (Table 5), yet no such evidence for benzene or the rest has been detected.

\section{COMPARATIVE METAGENOMIC ANALYSIS}

Clustering on (KEGG) functional gene categories was conducted among different environmental samples (Figure 3). Guaymas chimney sample 4558-6 (4510962.3) was clustered most closely with chimney sample from Juan de Fuca (4510965.3). Both of these two metagenomes were almost depleted in categories of RNA family and folding, sorting and degradation, while they showed higher abundance in the categories of signaling molecules, and interaction and cell communication. These features might be highly related to the specific environmental conditions where these two chimney samples were collected. The metagenome of the Lost City chimney sample (4461585.3) was not grouped with the above two chimney samples. The two biofilm samples from acid mine drainage (4441137.3 and 4441138.3) shared similar functional profiles in the heatmap, adjacent to the chimney sample from Lost City and the gutless worm sample (4441115.3). Samples from the North Pacific Subtropical Gyre microbial communities (4441051.3, 4441057.4, 4441055.3, 4441041.3, 4441057.3, 4441062.3, and 4441056.3) were grouped next to each other in the functional heatmap, and a similar pattern was observed for Peru Margin sediments samples (4440960.3, 4440961.3, 4440973.3, 4459940.3, and 4459941.3). Enzymes involved in hydrocarbon biodegradation in metagenomes from different environments were listed in Table A3. When compared to metagenomes from different environments, 4458-6 from Guaymas hydrothermal vent chimney was the only one with enzymes for biodegradation of toluene, ethylbenzene, and o-xylene (Table A3), highlighting its metabolic 


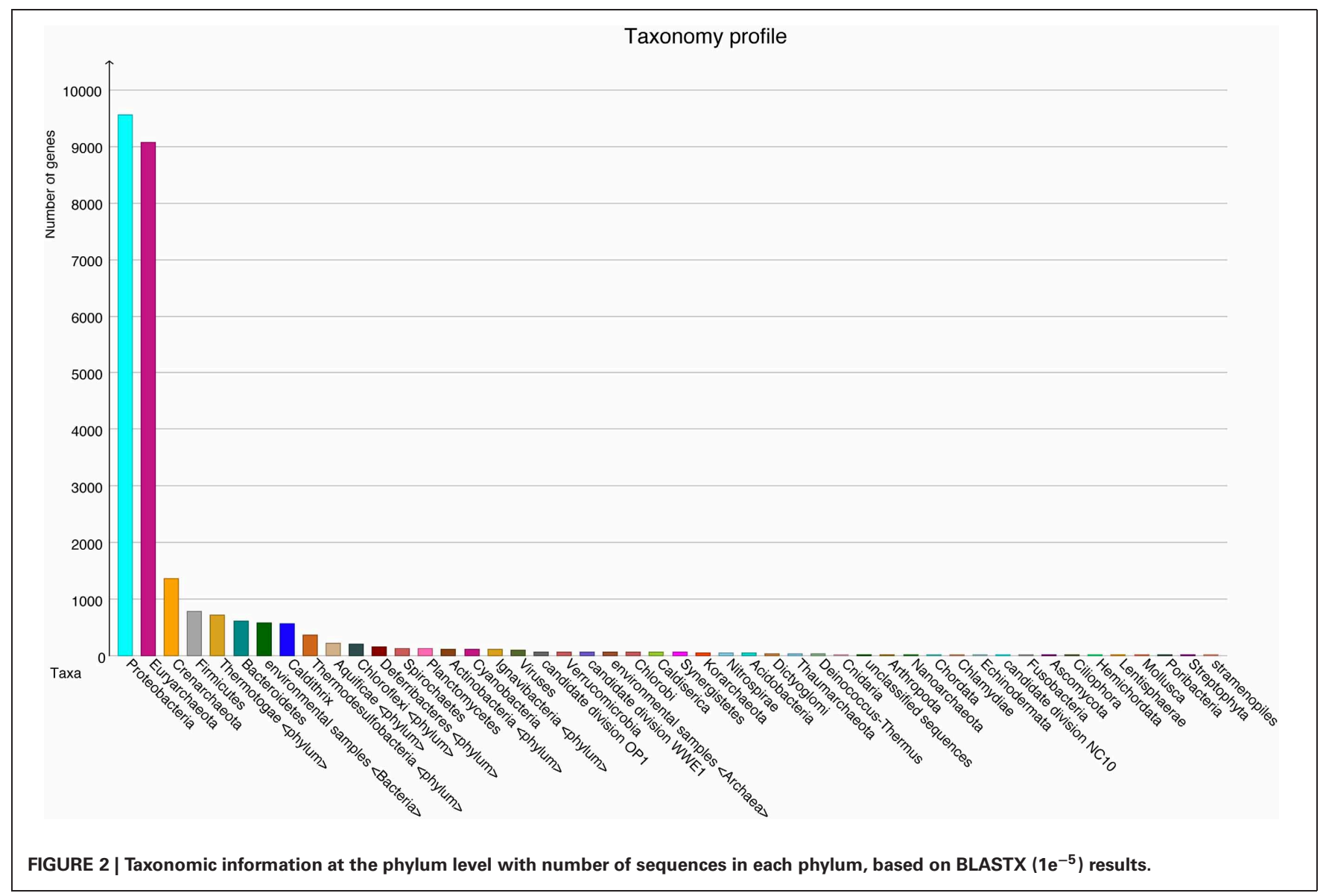

Table 3 | Top families with the most hits assigned.

\begin{tabular}{lcl}
\hline Family & $\begin{array}{l}\text { No. of hits } \\
\text { assigned (\%) }\end{array}$ & Phylum \\
\hline Archaeoglobaceae & $4777(12.78)$ & Euryarchaeota \\
Thermococcaceae & $2365(6.33)$ & Euryarchaeota \\
Desulfobacteraceae & $2117(5.66)$ & (Delta) Proteobacteria \\
Thermotogaceae & $723(1.93)$ & Proteobacteria \\
Desulfurococcaceae & $672(1.80)$ & Crenarchaeota \\
Helicobacteraceae & $375(1.00)$ & (Epsilon) Proteobacteria \\
Thermodesulfobacteriaceae & $355(0.95)$ & Proteobacteria \\
Colwelliaceae & $344(0.92)$ & (Gamma) Proteobacteria \\
Thiotrichaceae & $214(0.57)$ & (Gamma) Proteobacteria \\
Desulfovibrionaceae & $208(0.56)$ & (Delta) Proteobacteria \\
Sulfate reducing prokaryotes & $7921 *(21.2)$ & - \\
\hline
\end{tabular}

The exact number of blast hits was listed for each family, with the percentages (out of total hits) listed in the parentheses.

*The number of hits for SRP was generated by summing all the hits from Archaeoglobaceae, Desulfobacteraceae, Desulfurococcaceae, Desulfovibrionaceae, and Thermodesulfobacteriaceae.

potential in degrading hydrocarbons in the native oil-immersed condition.

\section{DISCUSSION}

Advances in sequencing technologies have made microbial diversity studies easier and more accurate. However, biases were introduced during sequencing and analyzing of environmental sequences. For instance, biases were generated when multiple reads were produced for a unique DNA fragment in a random manner. Such biases might result in an inaccurate representation of the fragments and lead to misleading conclusions. Therefore, strict quality control of the sequenced reads should be done. In this study, a decent sequencing coverage has been reached (Figure 1) and we are in the position to investigate the taxonomic diversity as well as the metabolic potential of this Guaymas chimney sample.

\section{DIVERSITY AT DIFFERENT TAXONOMIC LEVELS}

Estimated from both 16S rRNA sequences as well as taxonomic classifications based on blast hits, the proportion of bacteria in the community was about $60-75 \%$, and $25-30 \%$ for archaea. Bacteria were dominated by Proteobacteria, while Euryarchaeota were most abundant among the archaea. So far, sulfate-reducing bacteria and archaea have been isolated in vent chimneys, with either high or low growth temperature $\left(30-90^{\circ} \mathrm{C}\right.$ ) (Burggraf et al., 1990; Audiffrin et al., 2003; Moussard et al., 2004). Sulfate reduction may occur at temperatures up to $110^{\circ} \mathrm{C}$ in hot sediments from Guaymas hydrothermal field (Jørgensen et al., 1992). In this study, a high proportion (at least 21.2\%) of sequences from this chimney metagenome was potentially originated from SRP (Table 3), a large and extremely diverse physiological group of anaerobic microorganisms. Sulfate-reducing bacteria and archaea 
were capable of degrading a wide range of organic substrates (Widdel and Bak, 1992; Widdel and Rabus, 2001), including petroleum-based products that were discussed in this study. The presence of large numbers of SRP in the oil-immersed chimney suggested that the microbial community had the potential of hydrocarbon biodegradation, which were likely to be coupled with sulfate reduction. Besides, most of the retrieved sequences were estimated to originate from thermophilc microorganisms such as Archaeoglobus, heterotrophic Thermococcales and Thermodesulfobacteriaceae, reflecting the influence of the high temperature on the structure of the microbial community.

\section{Table 4 | List of major KEGG families.}

\begin{tabular}{|c|c|c|c|}
\hline $\begin{array}{l}\text { KEGG (level 2) } \\
\text { annotation }\end{array}$ & Avg. \% ident & $\begin{array}{l}\text { Avg. aligned } \\
\text { len. }\end{array}$ & No. of hits \\
\hline Amino acid metabolism & 69.68 & 80.99 & 1756 \\
\hline Carbohydrate metabolism & 69.96 & 75.17 & 1365 \\
\hline Translation & 71.01 & 66.33 & 1301 \\
\hline Membrane transport & 68.01 & 70.23 & 836 \\
\hline $\begin{array}{l}\text { Metabolism of cofactors } \\
\text { and vitamins }\end{array}$ & 68.73 & 71.72 & 723 \\
\hline Energy metabolism & 72.02 & 73.84 & 689 \\
\hline Nucleotide metabolism & 68.99 & 68.01 & 550 \\
\hline Replication and repair & 67.7 & 71.41 & 515 \\
\hline $\begin{array}{l}\text { Folding, sorting and } \\
\text { degradation }\end{array}$ & 71.9 & 71.82 & 386 \\
\hline Signal transduction & 67.86 & 62.85 & 375 \\
\hline Cell motility & 70.33 & 57.04 & 258 \\
\hline $\begin{array}{l}\text { Glycan biosynthesis and } \\
\text { metabolism }\end{array}$ & 67 & 65.77 & 240 \\
\hline Transcription & 73.36 & 75.02 & 213 \\
\hline Cell growth and death & 68.78 & 64.14 & 209 \\
\hline Lipid metabolism & 70.28 & 64.61 & 184 \\
\hline
\end{tabular}

Average sequence identity (Avg \% ident) and aligned sequence length (Avg aligned len) were presented. No. of Hits represented the number of unique hits within each functional protein category. Uncharacterized proteins were excluded.

\section{METABOLIC POTENTIAL FOR HYDROCARBON DEGRADATION}

Deep-sea environments have been characterized by the lack of easily biodegradable OM, thus genes related to the degradation of refractory OM have been extensively recovered from the metagenomes of deep oceans (Martin-Cuadrado et al., 2007). Moreover, bacteria isolated from the deep sea have been shown to be capable of degrading refractory OM such as chitin and cellulose (Hedges et al., 2000; Vezzi et al., 2005; Wang et al., 2008). Here, the potential of a chimney microbial community for refractory OM degradation was evaluated. Genes coding for chitin degradation were not found in the metagenome, while all the genes involved in the degradation of cellulose and fatty acids, as well as a few key enzymes in the breakdown of lipid and pullulan were identified, which probably reflected in part the input of terrestrial OM circulating in this Guaymas vent field. As most of the identified enzymes had a presumably thermophilic origin (Table 5 and Table A2), and thermophilic microorganisms were predominant in the chimney sample (Table 3), it was likely that these enzymes had some degree of heat tolerance. Additionally, microorganisms of this Guaymas chimney were predicted to have the potential to degrade toluene, ethylbenzene, and o-xylene. Notably, anaerobic hydrocarbon degrading microorganisms have been successfully enriched and most extensively studied with the benzene-toluene-ethylbenzenexylenes (BTEX) group of petroleum hydrocarbons (Stockton et al., 2009). For example, pure culture strain EbS7 was isolated from the sediments of Guaymas Basin which was reported with the ethylbenzene-dependent sulfate reduction (Kniemeyer et al., 2003). This Guaymas chimney sample was oil immersed, thus it was not surprising to see the presence of genes involved in the degradations of petroleum hydrocarbons (Table 5). Our data further highlighted the potential of this microbial community using the fumarate addition pathway for the degradation of aromatic and aliphatic hydrocarbons. Identification of genes coding for hydrocarbon degradation would advance characterizations of the potential source of electrons and energy, as well as the roles of this chimney microbial community had played in its native environment. Notably, this Guaymas chimney

Table 5 | List of annotated gene features involved in degradation of hydrocarbons, absense of gene was marked with "-".

\begin{tabular}{|c|c|c|c|c|}
\hline Substrate & Enzyme (EC) & Best hit contig & Metagenome best hit organism & Similarity \% (e-value) \\
\hline n-Alkanes & assA2 & Contig45077 & Desulfoglaeba alkanexedens AK-01 & $95(9 e-10)$ \\
\hline \multirow[t]{4}{*}{ Aromatic hydrocarbons } & bssA & Contig28667 & Desulfotomaculum sp. Ox39 & $76(1.7 e-6)$ \\
\hline & $b s s B$ & - & - & - \\
\hline & bssC & Contig46590 & Desulfatibacillum alkenivorans AK-01 & $35(2 e-7)$ \\
\hline & $b s s G$ & Contig46590 & Desulfatibacillum alkenivorans AK-01 & $79(1 e-6)$ \\
\hline Toluene & toluene 4-monooxygenase & Contig31764 & Dechloromonas aromatica (strain $R C B$ ) & $77(1.6 e-64)$ \\
\hline Ethylbenzene & ethylbenzene dehydrogenase & Contig32722 & Desulfococcus oleovorans Hxd3 & $86(3.4 \mathrm{e}-145)$ \\
\hline
\end{tabular}




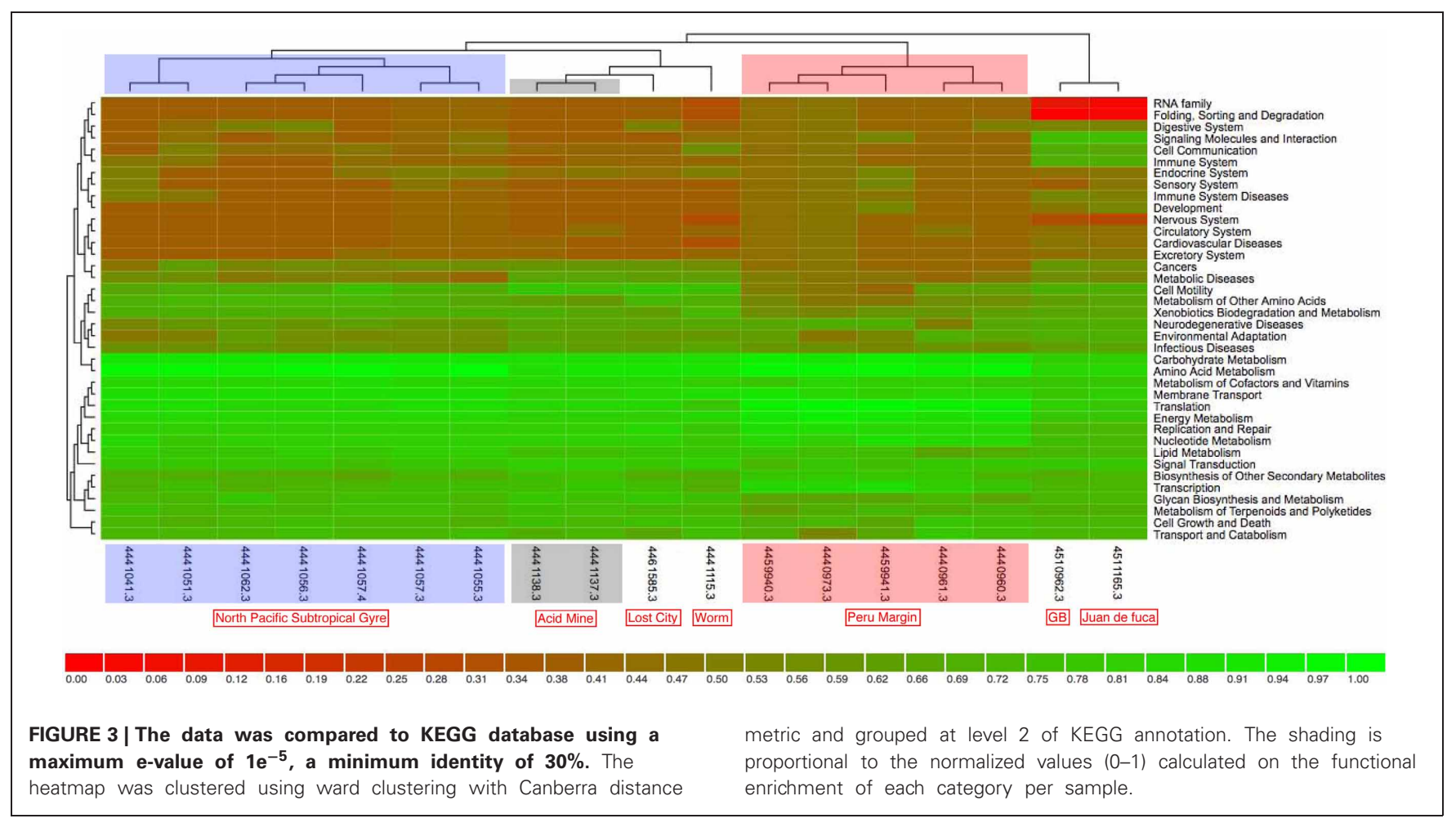

metagenome seemed to be the only one (among all the samples included in the comparative metagenomic analysis) with metabolic potential for hydrocarbons biodegradation (Table A3). Enzymes activated by oxygen (namely active under aerobic conditions) were not identified in our metagenome, consistent with the strict anaerobic condition where this chimney sample was collected. Metagenomic analysis suggested that degradation of a variety of petroleum hydrocarbons by SRP might play an important role in the energy metabolism of this chimney microbial community.

\section{COMPARISON AMONG DIFFERENT SAMPLES}

For the moment, only three metagenomes from hydrothermal vent chimney are available, one from Juan de Fuca (Xie et al., 2011), one from Lost City (Brazelton and Baross, 2009) and the last one was our chimney sample 4458-6 from Guaymas Basin. The whole metagenome-based comparison (Figure 3) showed that Lost City was not clustered next to the other two chimney samples, which could be due to the fact that the Lost City sample was collected from a white carbonate chimney (CC) rather than a back sulfide chimney (SC) as the other two samples were. When considering the fact that the dominant energy sources for SC and CC were significant different (i.e., metal sulfides in SC and reduced volatiles such as hydrogen, methane in $\mathrm{CC}$, respectively), the genomic differences between the two types of chimneys become clear as different energy metabolisms were promoted accordingly. Moreover, the venting fluid of Lost City had a $\mathrm{pH}$ of $9-11$ and temperatures lower than $90^{\circ} \mathrm{C}$, whereas that of Juan de Fuca sample was acidic and hot (temperature around $310^{\circ} \mathrm{C}$ ); the vent fluid of our Guaymas chimney sample represented an intermediate temperature regime $\left(190^{\circ} \mathrm{C}\right)$. Differences in environmental factors (such as temperature, $\mathrm{pH}$, and physico-chemical gradients) between white and black chimneys could also have a significant influence on the distribution of functional gene categories, and as a result the three chimney samples were not clustered next to each other. On the other hand, when looking at specific gene categories, metagenomes from hydrothermal vent chimneys (Guaymas Basin, Juan de Fuca and Lost City) kept a larger collection of genes involved in recombination and repair, chemotaxis and flagellar assembly, as well as transposases. This could be a chimney-specific feature, reflecting adaptations of microorganisms and the microbial community to the extreme fluctuating chemical and physical conditions that characterize deep-sea hydrothermal vent chimneys.

\section{ACKNOWLEDGMENTS}

We thank Anna-Louise Reysenbach for providing the chance to attend the expedition, and all the crew members from R/V Atlantis/DSV Alvin on the Guaymas Basin Expedition 2009 for collecting the samples. This research was supported by the National High Technology Research and Development Program of China (Grant No. 2012AA092103-2), China Ocean Mineral Resources R \& D Association (Grant No.DYXY-1258-YP-2), National Basic Research Program of China (Grant No.2011CB808800), National Science Foundation of China (Grant No. 91228201 and 31290232), "ShuGuang" Project supported by Shanghai Municipal Education Commission and Shanghai Education Development Foundation, and the US-NSF (OCE-0728391) to Anna-Louise Reysenbach. 


\section{REFERENCES}

Altschul, S. F., Madden, T. L., Schaffer, A. A., Zhang, J., Zhang, Z., Miller, W., et al. (1997). Gapped BLAST and PSI-BLAST: a new generation of protein database search programs. Nucleic Acids Res. 25, 3389-3402. doi: 10.1093/nar/25.17.3389

Amann, R. I., Ludwig, W., and Schleifer, K. H. (1995). Phylogenetic identification and in situ detection of individual microbial cells without cultivation. Microbiol. Rev. 59, 143-169.

Audiffrin, C., Cayol, J. L., Joulian, C., Casalot, L., Thomas, P., Garcia, J. L., et al. (2003). Desulfonauticus submarinus gen. nov., sp. nov., a novel sulfate-reducing bacterium isolated from a deep-sea hydrothermal vent. Int. J. Syst. Evol. Microbiol. 53, 1585-1590.

Bazylinski, D. A., Farrington, J. W., and Jannasch, H. W. (1988). Hydrocarbons in surface sediments from a Guaymas Basin hydrothermal vent site. Org. Geochem. 12, 547-559. doi: 10.1016/0146-6380(88)90146-5

Biddle, J. F., Fitz-Gibbon, S., Schuster, S. C., Brenchley, J. E., and House, C. H. (2008). Metagenomic signatures of the Peru Margin subseafloor biosphere show a genetically distinct environment. Proc. Natl. Acad. Sci. U.S.A. 105, 10583-10588. doi: 10.1073/pnas.0709942105

Brazelton, W. J., and Baross, J. A. (2009). Abundant transposases encoded by the metagenome of a hydrothermal chimney biofilm. ISME J. 3, 1420-1424. doi: 10.1038/ismej.2009.79

Brazelton, W. J., Ludwig, K. A., Sogin, M. L., Andreishcheva, E. N., Kelley, D. S., Shen, C. C., et al. (2010). Archaea and bacteria with surprising microdiversity show shifts in dominance over 1,000-year time scales in hydrothermal chimneys. Proc. Natl. Acad. Sci. U.S.A. 107, 1612-1617. doi: 10.1073/pnas.0905369107

Burggraf, S., Jannasch, H. W., Nicolaus, B., and Stetter, K. O. (1990). Archaeoglobus profundus sp. nov., represents a new species within the sulfate-reducing Archaebacteria. Syst. Appl. Microbiol. 13, 24-28. doi: 10.1016/S0723-2020(11)80176-1

Callaghan, A. V., Davidova, I. A., Savage-Ashlock, K., Parisi, V. A., Gieg, L. M., Suflita, J. M., et al. (2010). Diversity of benzyland alkylsuccinate synthase genes in hydrocarbon-impacted environments and enrichment cultures. Environ. Sci. Technol. 44, 7287-7294. doi: 10.1021/es1002023
Delong, E. F., Preston, C. M., Mincer, T., Rich, V., Hallam, S. J., Frigaard, N. U., et al. (2006). Community genomics among stratified microbial assemblages in the ocean's interior. Science 311, 496-503. doi: 10.1126/science.1120250

Dick, G. J., and Tebo, B. M. (2010). Microbial diversity and biogeochemistry of the Guaymas Basin deep-sea hydrothermal plume. Environ. Microbiol. 12, 1334-1347.

Distel, D. L., Lane, D. J., Olsen, G. J., Giovannoni, S. J., Pace, B., Pace, N. R., et al. (1988). Sulfur-oxidizing bacterial endosymbionts: analysis of phylogeny and specificity by $16 \mathrm{~S}$ rRNA sequences. J. Bacteriol. 170, 2506-2510.

Elsgaard, L., Isaksen, M. F., Jørgensen, B. B., Alayse, A. M., and Jannasch, H. W. (1994). Microbial sulfate reduction in deep-sea sediments at the Guaymas Basin hydrothermal vent area: influence of temperature and substrates. Geochim. Cosmochim. Acta 58, 3335-3343. doi: 10.1016/0016-7037(94)90089-2

Flores, G. E., Campbell, J. H., Kirshtein, J. D., Meneghin, J., Podar, M., Steinberg, J. I., et al. (2011). Microbial community structure of hydrothermal deposits from geochemically different vent fields along the Mid-Atlantic Ridge. Environ. Microbiol. 13, 2158-2171. doi: 10.1111/j.1462-2920.2011.02463.x

Galushko, A., Minz, D., Schink, B., and Widdel, F. (1999). Anaerobic degradation of naphthalene by a pure culture of a novel type of marine sulphate-reducing bacterium. Environ. Microbiol. 1, 415-420. doi: 10.1046/j.1462-2920.1999.00051.x

Gao, J., Ellis, L. B., and Wackett, L. P. (2010). The University of Minnesota Biocatalysis/Biodegradation Data base: improving public access. Nucleic Acids Res. 38, D488-D491. doi: 10.1093/nar/gkp771

Gomez-Alvarez, V., Teal, T. K., and Schmidt, T. M. (2009). Systematic artifacts in metagenomes from complex microbial communities. ISME J. 3, 1314-1317. doi: 10.1038/ismej.2009.72

He, Z., Deng, Y., Van Nostrand, J. D., Tu, Q., Xu, M., Hemme, C. L., et al. (2010). GeoChip 3.0 as a high-throughput tool for analyzing microbial community composition, structure and functional activity. ISME J. 4, 1167-1179. doi: 10.1038/ismej.2010.46

Hedges, J. I., Eglinton, G., Hatcher, P. G., Kirchman, D. L., Arnosti, C., Derenne, S., et al. (2000). The molecularly-uncharacterized component of nonliving organic matter in natural environments. Org. Geochem. 31, 945-958. doi 10.1016/S0146-6380(00)00096-6

Huber, J. A., Cantin, H. V., Huse, S. M., Welch, D. B., Sogin, M. L., and Butterfield, D. A. (2010). Isolated communities of Epsilonproteobacteria in hydrothermal vent fluids of the Mariana Arc seamounts. FEMS Microbiol. Ecol. 73, 538-549. doi 10.1111/j.1574-6941.2010.00910.x

Huber, J. A., Mark Welch, D. B. Morrison, H. G., Huse, S. M., Neal, P. R., Butterfield, D. A., et al. (2007). Microbial population structures in the deep marine biosphere. Science 318, 97-100. doi 10.1126/science.1146689

Huson, D. H., Auch, A. F., Qi, J., and Schuster, S. C. (2007). MEGAN analysis of metagenomic data. Genome Res. 17, 377-386. doi 10.1101/gr.5969107

Jannasch, H. W., and Mottl, M. J. (1985). Geomicrobiology of deep-sea hydrothermal vents. Science 229, 717-725. doi: 10.1126/science.229.4715.717

Jørgensen, B. B., Isaksen, M. F., and Jannasch, H. W. (1992) Bacterial sulfate reduction above 100 \{degrees\}C in deepsea hydrothermal vent sediments. Science 258, 1756-1757. doi: 10.1126/science.258.5089.1756

Jørgensen, B. B., Zawacki, L. X., and Jannasch, H. W. (1990) Thermophilic bacterial sulfate reduction in deep-sea sediments at the Guaymas Basin hydrothermal vents (Gulf of California). Deep-Sea Res. I 37, 695-710. doi 10.1016/0198-0149(90)90099-H

Kallmeyer, J., and Boetius, A. (2004). Effects of temperature and pressure on sulfate reduction and anaerobic oxidation of methane in hydrothermal sediments of Guaymas Basin. Appl. Environ. Microbiol. 70, 1231-1233. doi: 10.1128/AEM.70.2.1231-1233.2004

Kawka, O. E., and Simoneit, B. R. T. (1994). Hydrothermal pyrolysis of organic matter in Guaymas Basin. I. Comparison of hydrocarbon distributions in subsurface sediments and seabed petroleums. Org. Geochem. 22, 947-978. doi: 10.1016/01466380(94)90031-0

Kleindienst, S., Ramette, A., Amann, R., and Knittel, K. (2012). Distribution and in situ abundance of sulfate-reducing bacteria in diverse marine hydrocarbon seep sediments. Environ. Microbiol. 14, 2689-2710. doi 10.1111/j.1462-2920.2012.02832.x
Kniemeyer, O., Fischer, T., Wilkes, H., Glockner, F. O., and Widdel, F. (2003). Anaerobic degradation of ethylbenzene by a new type of marine sulfatereducing bacterium. Appl. Environ. Microbiol. 69, 760-768. doi: 10.1128/AEM.69.2.760-768.2003

Lam, P., Cowen, J. P., and Jones, R. D. (2004). Autotrophic ammonia oxidation in a deep-sea hydrothermal plume. FEMS Microbiol. Ecol. 47, 191-206. doi: 10.1016/S01686496(03)00256-3

Martens, C. S. (1990). Generation of short chain organic acid anions in hydrothermally altered sediments of the Guaymas Basin, Gulf of California. Appl. Geochem. 5, 71-76. doi: 10.1016/0883-2927(90) 90037-6

Martin-Cuadrado, A. B., LopezGarcia, P., Alba, J. C., Moreira, D., Monticelli, L., Strittmatter, A., et al. (2007). Metagenomics of the deep Mediterranean, a warm bathypelagic habitat. PLOS ONE 2:e914. doi: 10.1371/journal.pone.0000914

Meyer, F., Paarmann, D., D'Souza, M. Olson, R., Glass, E. M., Kubal, M., et al. (2008). The metagenomics RAST server - a public resource for the automatic phylogenetic and functional analysis of metagenomes. BMC Bioinformatics 9:386. doi: 10.1186/1471-2105-9386

Moussard, H., L'Haridon, S., Tindall, B. J., Banta, A., Schumann, P., Stackebrandt, E., et al. (2004). Thermodesulfatator indicus gen. nov., sp. nov., a novel thermophilic chemolithoautotrophic sulfatereducing bacterium isolated from the Central Indian Ridge. Int. J. Syst. Evol. Microbiol. 54, 227-233. doi: 10.1099/ijs.0.02669-0

Musat, F., and Widdel, F. (2008). Anaerobic degradation of benzene by a marine sulfatereducing enrichment culture, and cell hybridization of the dominant phylotype. Environ. Microbiol. 10, 10-19. doi 10.1111/j.1462-2920.2007.01425.x

Niu, B., Fu, L., Sun, S., and Li, W. (2010). Artificial and natural duplicates in pyrosequencing reads of metagenomic data. BMC Bioinformatics 11:187. doi: 10.1186/1471-2105-11-187

Ogata, H., Goto, S., Sato, K., Fujibuchi, W., Bono, H., and Kanehisa, M. (1999). KEGG: kyoto encyclopedia of genes and genomes. Nucleic Acids Res. 27, 29-34. doi: 10.1093/nar/27.1.29

Petersen, J. M., Zielinski, F. U., Pape, T., Seifert, R., Moraru, C., Amann, R. 
et al. (2011). Hydrogen is an energy source for hydrothermal vent symbioses. Nature 476, 176-180. doi: 10.1038/nature10325

Powell, S., Szklarczyk, D., Trachana, K., Roth, A., Kuhn, M., Muller, J., et al. (2012). eggNOG v3.0: orthologous groups covering 1133 organisms at 41 different taxonomic ranges. Nucleic Acids Res. 40, D284-D289. doi: 10.1093/nar/gkr1060

Reysenbach, A. L., and Shock, E. (2002). Merging genomes with geochemistry in hydrothermal ecosystems. Science 296, 1077-1082. doi: 10.1126/science. 1072483

Rho, M., Tang, H., and Ye, Y. (2010). FragGeneScan: predicting genes in short and error-prone reads. Nucleic Acids Res. 38:e191. doi: 10.1093/nar/gkq747

Roussel, E. G., Konn, C., Charlou, J. L., Donval, J. P., Fouquet, Y., Querellou, J., et al. (2011). Comparison of microbial communities associated with three Atlantic ultramafic hydrothermal systems. FEMS Microbiol. Ecol. 77, 647-665. doi: 10.1111/j.1574-6941.2011.01161.x

Rüter, P., Rabus, R., Wilkes, H., Aeckersberg, F., Rainey, F. A., Jannasch, H. W., et al. (1994). Anaerobic oxidation of hydrocarbons in crude oil by new types of sulphate-reducing bacteria. Nature 372, 455-458. doi: $10.1038 / 372455 \mathrm{a} 0$

Stockton, A. M., Chiesl, T. N., Scherer, J. R., and Mathies, R. A. (2009). Polycyclic aromatic hydrocarbon analysis with the Mars organic analyzer microchip capillary electrophoresis system. Anal. Chem. 81, 790-796. doi: 10.1021/ac802033u

Tatusov, R. L., Fedorova, N. D., Jackson, J. D., Jacobs, A. R.,
Kiryutin, B., Koonin, E. V., et al. (2003). The COG database: an updated version includes eukaryotes. BMC Bioinformatics 4:41. doi: 10.1186/1471-2105-4-41

Teske, A., Hinrichs, K. U., Edgcomb, V., De Vera Gomez, A., Kysela, D. Sylva, S. P., et al. (2002). Microbial diversity of hydrothermal sediments in the Guaymas Basin: evidence for anaerobic methanotrophic communities. Appl. Environ. Microbiol. 68, 1994-2007.

Tyson, G. W., Chapman, J., Hugenholtz, P., Allen, E. E., Ram, R. J., Richardson, P. M., et al. (2004). Community structure and metabolism through reconstruction of microbial genomes from the environment. Nature 428, 37-43. doi: $10.1038 /$ nature02340

Vezzi, A., Campanaro, S., D’Angelo, M., Simonato, F., Vitulo, N., Lauro, F. M., et al. (2005). Life at depth: photobacterium profundum genome sequence and expression analysis. Science 307, 1459-1461. doi: 10.1126/science. 1103341

Von Damm, K. L. (1990). Seafloor hydrothermal activity: black smoker chemistry and chimneys. Annu. Rev. Earth Planet Sci. 18, 173-204. doi: 10.1146/annurev.ea.18.050190. 001133

Von Damm, K. L., Edmond, J. M., Measures, C. I., and Grant, B. (1985). Chemistry of submarine hydrothermal solutions at Guaymas Basin, Gulf of California Geochimica et Cosmochimica Acta 49, 2221-2237. doi: 10.1016/0016-7037(85)90223-6

Wang, F., Wang, J., Jian, H., Zhang, B., Li, S., Wang, F., et al. (2008). Environmental adaptation: genomic analysis of the piezotolerant and psychrotolerant deep-sea iron reducing bacterium Shewanella piezotolerans WP3. PLoS ONE 3:e1937. doi: 10.1371/journal.pone. 0001937

Wang, F., Zhou, H., Meng, J., Peng, X., Jiang, L., Sun, P., et al. (2009). GeoChip-based analysis of metabolic diversity of microbial communities at the Juan de Fuca Ridge hydrothermal vent. Proc. Natl. Acad. Sci. U.S.A. 106, 4840-4845. doi: 10.1073/pnas. 0810418106

Weber, A., and Jørgensen, B. B. (2002). Bacterial sulfate reduction in hydrothermal sediments of the Guaymas Basin, Gulf of California, Mexico. Deep Sea Res. I 149, 827-841.

Welhan, J. A. (1988). Origins of methane in hydrothermal systems. Chem. Geol. 71, 183-198.

Widdel, F., and Bak, F. (1992). "Gram-negative mesophilic sulfate-reducing bacteria," in The Prokaryotes, eds A. Balows, $\mathrm{H}$. G. Trüper, M. Dworkin, W. Harder, and K.H. Schleifer (New York, NY: Springer-Verlag), 3352-3378.

Widdel, F., and Rabus, R. (2001). Anaerobic biodegradation of saturated and aromatic hydrocarbons. Curr. Opin. Biotechnol. 12, 259-276.

Woyke, T., Teeling, H., Ivanova, N. N., Huntemann, M., Richter, M., Gloeckner, F. O., et al. (2006). Symbiosis insights through metagenomic analysis of a microbial consortium. Nature 443, 950-955. doi: 10.1038/nature05192

Wu, S., Zhu, Z., Fu, L., Niu, B., and $\mathrm{Li}, \mathrm{W}$. (2011). WebMGA: a customizable web server for fast metagenomic sequence analysis.
BMC Genomics 12:444. doi: 10.1186/1471-2164-12-444

Xie, W., Wang, F., Guo, L., Chen, Z., Sievert, S. M., Meng, J., et al. (2011). Comparative metagenomics of microbial communities inhabiting deep-sea hydrothermal vent chimneys with contrasting chemistries. ISME J. 5, 414-426. doi: 10.1038/ismej. 2010.144

Zerbino, D. R., and Birney, E. (2008). Velvet: algorithms for de novo short read assembly using de Bruijn graphs. Genome Res. 18, 821-829. doi: 10.1101/gr.074492.107

Conflict of Interest Statement: The authors declare that the research was conducted in the absence of any commercial or financial relationships that could be construed as a potential conflict of interest.

Received: 30 January 2013; accepted: 27 May 2013; published online: 14 June 2013.

Citation: He Y, Xiao $X$ and Wang $F$ (2013) Metagenome reveals potential microbial degradation of hydrocarbon coupled with sulfate reduction in an oilimmersed chimney from Guaymas Basin. Front. Microbiol. 4:148. doi: 10.3389/ fmicb.2013.00148

This article was submitted to Frontiers in Extreme Microbiology, a specialty of Frontiers in Microbiology.

Copyright (c) $2013 \mathrm{He}$, Xiao and Wang. This is an open-access article distributed under the terms of the Creative Commons Attribution License, which permits use, distribution and reproduction in other forums, provided the original authors and source are credited and subject to any copyright notices concerning any third-party graphics etc. 


\section{APPENDIX}

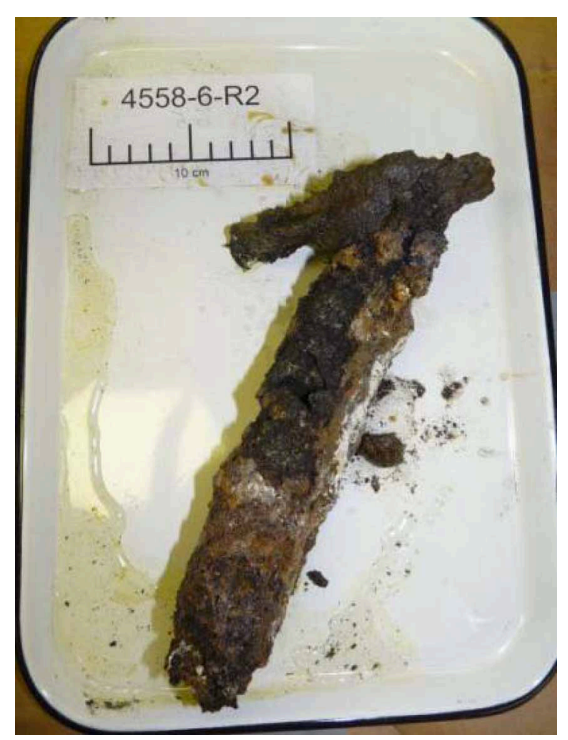

FIGURE A1 | The photo of a black-smoker chimney sample (4558-6), collected in Guaymas Basin $\left(27^{\circ} 0.9^{\prime} \mathrm{N}, 111^{\circ} 24.6^{\prime} \mathrm{W}\right.$, depth $\left.=2013 \mathrm{~m}\right)$.

Table A1 | Taxonomic information based on assigned blastx results to each domain.

\begin{tabular}{lll}
\hline Domain & No. of hits assigned & \% of hits assigned \\
\hline Bacteria & 21792 & 58.3 \\
Archaea & 11249 & 30.1 \\
Eukaryota & 224 & 0.6 \\
Virus & 88 & 0.2 \\
Unassigned & 4019 & 10.8 \\
\hline
\end{tabular}


Table A2 | List of annotated protein features involved in degradation processes.

Substrate: step enzym

Best BLAST hit organism

STEP [CELLULOSE]: $\rightarrow$ CELLULOSE CELLOBIOSE

Endo-1,4-beta-glucanase

Thermotoga neapolitana*

Cellulase

Thermosipho melanesiensis B1429*

Methanococcoides burtonii DSM 6242

Endoglucanase

Archaeoglobus fulgidus DSM 4304*

Cellobiose $\rightarrow$ beta-D-Glucose

Beta-glucosidase

STEP [FATTY ACIDS]: FATTY ACIDS $\rightarrow$ HEXA-DECANOYL-COA

Long chain fatty acid CoA ligase

Dictyoglomus thermophilum H-6-12 (2)

Bacillus thuringiensis serovar huazhongensis BGSC 4BD1

Bacteroides sp.2_1_7

Bacillus cereus BDRD-ST196

Desulfobacterium autotrophicum HRM2(2)

Carboxydothermus hydrogenoformans Z-2901*

Archaeoglobus fulgidus DSM $4304(16)^{*}$

Acyl-CoA synthetase

Picrophilus torridus DSM 9790*

Syntrophus aciditrophicus $S B$

Desulfatibacillum alkenivorans AK-01

Archaeoglobus fulgidus DSM 4304 (6)*

Hexa-decanoyl-CoA $\rightarrow$ Trans-hexadec-2-enoyl-CoA

Acyl-CoA dehydrogenase

Pseudomonas aeruginosa PA7

Marinobacter algicola DG893

Colwellia psychrerythraea $34 \mathrm{H}$

Oceanobacter sp. RED65

Oceanospirillum sp. MED92

Gamma proteobacterium NOR51-B

Brucella abortus bv. 1 str. 9-941

Labrenzia alexandrii DFL-11

Brucella suis bv. 5 str. 513

Cytophaga hutchinsonii ATCC 33406

Candidatus Cloacamonas acidaminovorans

Bacillus clausii KSM-K16

Archaeoglobus fulgidus DSM 4304 (16)*

Trans-hexadec-2-enoyl-CoA $\rightarrow$ (S)-3-Hydroxy-hexa-decanoyl-CoA

Beta-hydroxyacyl-CoA dehydrase

Enoyl-CoA dydratase
Desulfuromonas acetoxidans DSM 684

Desulfococcus oleovorans Hxd3 (4)

Burkholderia multivorans CGD2M

Acidaminococcus sp. D21

Thermosinus carboxydivorans Nor 1

Desulfococcus oleovorans Hxd3 (4)

Desulfatibacillum alkenivorans AK-01

Geobacter bemidjiensis Bem

Candidatus Koribacter versatilis Ellin345

Marinomonas sp. MWYL1

Colwellia psychrerythraea $34 \mathrm{H}$

Carboxydothermus hydrogenoformans Z-2901*

Archaeoglobus fulgidus DSM 4304*

Rubrobacter xylanophilus DSM 9941 (2)* 


\section{Table A2 | Continued}

Substrate: step enzyme

(S)-3-Hydroxy-hexa-decanoyl-CoA $\rightarrow$ 3-Oxo-hexa-decanoyl-CoA

3-Hydroxyacyl-CoA dehydrogenase
Best BLAST hit organism

Gallionella ferruginea ES-2

Desulfococcus oleovorans Hxd3

Xanthobacter autotrophicus Py2

Rhodospirillum centenum SW

Geobacter uraniireducens Rf4

Archaeoglobus fulgidus DSM 4304 (12)*

Beta-hydroxyacyl dehydrogenase

Desulfococcus oleovorans Hxd3 (4)

Desulfuromonas acetoxidans DSM 684

3-Ketoacyl-CoA thiolase

Colwellia psychrerythraea $34 \mathrm{H}$

Halobacterium sp. NRC-1

Anaeromyxobacter dehalogenans $2 \mathrm{CP}-\mathrm{C}$

Archaeoglobus fulgidus DSM 4304 (6)*

Thiolase

Geobacter metallireducens GS-15

Polaromonas sp. JS666

\section{STEP [PULLULAN]: PULLULAN $\rightarrow$ PANOSE}

Pullulanase

Thermococcus onnurineus NA1(3)*

Thermococcus hydrothermalis*

Thermotoga sp. EMP

Amylopullulanase

Thermococcus sp. AM4*

\section{STEP [LIPID]: LIPID $\rightarrow$ GLYCEROL}

Glycerate kinase

Thermoanaerobacter sp. X513*

Aldehyde dehydrogenase

Desulfitobacterium dichloroeliminans LMG P-21439 Rhodothermus marinus SG0.5JP17-172

Melioribacter roseus P3M

Thermoplasma volcanium GSS1*

Calditerrivibrio nitroreducens DSM 19672

Uncultured Acidobacteria bacterium

Glycerol dehydrogenase

Archaeoglobus fulgidus DSM 4304*

Thermalphilic species were marked with an asterisk. 
Table A3 | List of enzymes involved in hydrocarbon biodegradation in metagenomes from different environments, presence was marked with "+," while absence with "-."

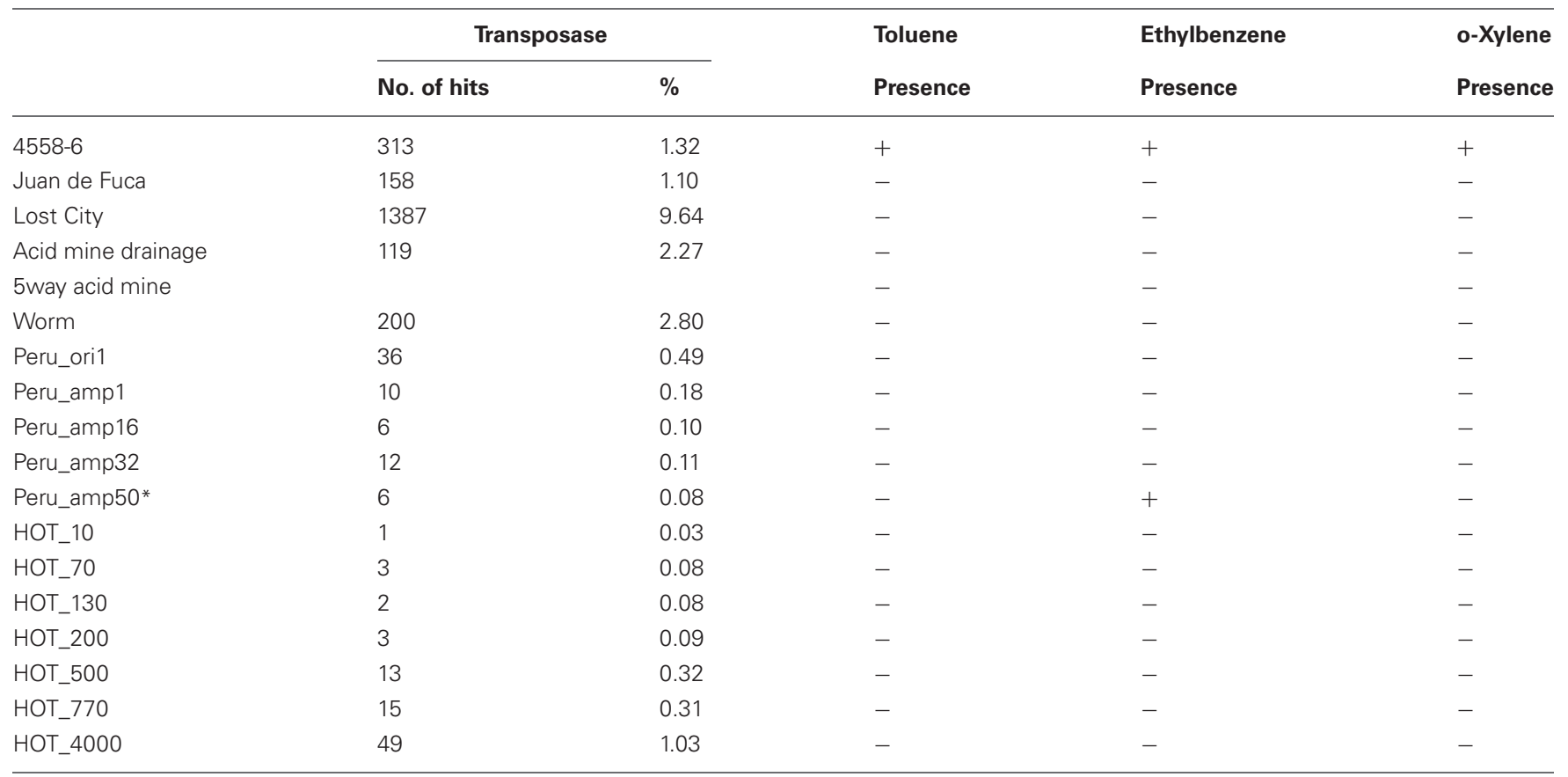

*Hit property: e-value 4.0 e-12, similarity $50 \%$, ethylbenzene dehydrogenase alpha subunit. 